C-SPAN. Access: http://www.c-span.org.

C-SPAN (or, in full, the Cable-Satellite Public Affairs Network) covers U.S. and world politics through its three separate cable channels, radio station, and podcasts. According to its Web site, "C-SPAN receives no government funding; operations are funded by fees paid by cable and satellite affiliates who carry C-SPAN programming." This allows C-SPAN to provide the most comprehensive and wide-ranging array of political programming, from U.S. Congressional hearings to British parliamentary sessions. The station can be considered America's network for unbiased and uninterrupted political reporting. By providing coverage of congressional and parliamentary sessions, C-SPAN allows viewers to make their own informed decisions on the political process.

C-SPAN became famous for its coverage of the U.S. Senate hearings at its inception in 1979, but the cable network has moved into the 21st century with an extensive Internet presence on its Web site. Political junkies of all persuasions can view live congressional hearings and parliamentary sessions from C-SPAN's three cable channels as well as a vast array of previously recorded hearings and sessions from an extensive video library. Each video has a brief explanation of the content, as well as useful related videos, giving the viewer a fuller account of the political process involved.

For example, Ben Bernanke's Federal Reserve statements on the U.S. economy contain relevant links to other hearings related to his testimony, such as hearings from U.S. Treasury Department officials. In addition to the vast video library, there are

Joni R. Roberts is associate university librarian for public services and collection development at Willamette University, e-mail: jroberts@willamette.edu, and Carol A. Drost is associate university librarian for technical services at Willamette University, e-mail: cdrost@ willamette.edu current topics to search, such as U.S. economic and energy policies, Supreme Court, as well as numerous historical series, such as first ladies in American history.

C-SPAN touts itself and its Web site as "Congress, Politics, Books and American History." For those who would rather use the Internet to learn more about these topics than watch television or listen to the radio, the C-Span Web site offers a vast array of relevant and current political and historical material easily available to anyone who enters its Web site-highly recommended for all who are interested in politics and the political process._Larry Cooperman, University of Central Florida Libraries, lawrence.cooperman@ucf.edu

FracFocus Chemical Disclosure Registry. $A C$ -

cess: http://fracfocus.org/.

FracFocus is a national registry for the disclosure of chemicals used in hydraulic fracturing, a technology used across the country to extend the productivity of natural gas and oil wells. The registry allows a user to search for gas and oil wells in a geographic area to see a listing of reported chemicals used. Beyond that, the site is a wealth of information on the hydraulic fracturing process and groundwater protection measures. It is cooperatively managed by the Ground Water Protection Council and the Interstate Oil and Gas Compact Commission.

Although a relatively new resource, "more than 200 energy-producing companies have registered over 15,000 well sites" in the first year and that number has now grown to more than 40,000 well sites. The registry is dynamic and will continue to "evolve and expand over time." The site has a clean and professional aesthetic, with an easy-to-navigate layout and interesting infographics supporting the text. Although the intended audience for the main content of the site is the general public-those with 
little or no prior knowledge regarding the purpose or process of hydraulic fracturing-the registry portion of the site was designed for more advanced users, as well.

When searching the registry, users can perform either a map search or a standard search to locate oil and gas wells. The map search is counterintuitive, however, as the map is not clickable until the user selects a state from the dropdown menu. Both search options provide the same dropdown menus to search by state, county, well name, and operator.

Advanced users, such as geologists or engineers, can also locate known wells by entering a well name or number. Wells that meet the criteria of the search are displayed, with a link to view the chemical disclosure document. Chemical disclosure documents include a list of reported chemical compounds used, the maximum concentrations used, and the purpose of each chemical compound in the hydraulic fracturing process.

FracFocus is an important chemical registry service for students and professionals in environmental sciences, earth sciences, and engineering. This up-to-date resource is one of the best ways to discover the location of oil and gas wells and the chemicals used at each site. It is also useful for accessing state regulations and contact information for local groundwater protection and oil and natural gas agencies.-Melissa J. Treichel, Willamette University, mtreiche@ willamette.edu

\section{Office of the United States Trade Representa-}

tive. Access: http://www.ustr.gov.

The Web site of the Office of the United States Trade Representative (USTR) is a good destination for finding current news and documentation on U.S. trade issues. As a resource for staying current with events and policy or a research gateway, USTR is a valuable tool.

Through eye-catching scrolling headlines and chronological lists of press re- leases, speeches, fact sheets, blog posts, and Federal Register notices, USTR highlights current trade topics. The agency's YouTube channel features key speeches and panel discussions, including presidential addresses. USTR also uses Twitter, Facebook, and other social media tools to connect with its audience.

Multilayered menus provide access to a deeper level of research. A "Trade Agreements" menu points to World Trade Organization, free trade agreements, and investment treaties pages. These pages provide introductory articles, links to relevant news items, reports, and key documents. A "Countries \& Regions" menu leads to individual country profiles with basic trade statistics and status of trade relations with the United States. Through the "Trade Topics" pages, the site features news, reports, and documents that relate to issues ranging from agriculture to textiles and apparel.

A "Trade Toolbox" serves as a guide to a library of resources for trade research, including a trade glossary and list of acronyms, a tariff database, key U.S. and international trade legislation, and links to other government Web sites for country reports and data. For researching older trade topics, the site links to an archived USTR Web site with similar access to news and reports from 2001 to 2009.

The site's menus allow for drilling more deeply into topics, moving from basic overview articles into more specific topics and government sources. It can also be easy to get caught in a maze while browsing through the layers of menus. The basic and advanced search features of USTR provide more direct access via keyword and exact phrase searching.

As a resource for staying current with trade issues from a U.S. perspective or as an entry point for researching policy and legislation, the U.S. Trade Representative's Web site is a worthy addition to an academic librarian's list of resources.-Ann Flower, Monterey Institute of International Studies,aflower@miis.edu $\mathbf{n}$ 